\title{
G Protein-Coupled Receptor 30 (GPR30) Expression Pattern in Inflammatory Bowel Disease Patients Suggests its Key Role in the Inflammatory Process. A Preliminary Study
}

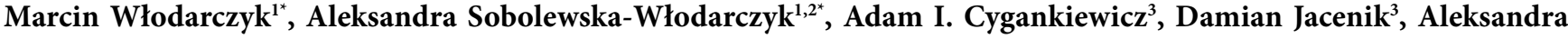 \\ Piechota-Polańczyk ${ }^{2}$, Krystyna Stec-Michalska ${ }^{2}$, Wanda M. Krajewska ${ }^{3}$, Jakub Fichna ${ }^{1}$, Maria Wiśniewska-Jarosińska ${ }^{2}$
}

1) Department of

Biochemistry, Medical

University of Lodz,

2) Department of

Gastroenterology, Medical

University of Lodz,

3) Department of

Cytobiochemistry, Faculty of

Biology and Environmental

Protection, University of Lodz, Lodz, Poland

\footnotetext{
Address for correspondence: Marcin Włodarczyk, MD Department of Biochemistry, Medical University of Lodz, Mazowiecka 6/8, 92-95 Lodz, Poland

dr.mwlodarczyk@gmail.com
}

\begin{abstract}
Background \& Aims: G protein-coupled receptor 30 (GPR30) is a recently de-orphanized estrogen receptor that mediates the effects of estrogens on different cells. It has been postulated that in inflammatory bowel diseases (IBD) activation of GPR30 blocks the pathways dependent on pro-inflammatory cytokines. The aim of our study was to investigate GPR30 expression in patients with IBD and its potential implication in future therapies.

Methods. Fifty-seven patients were enrolled in our study: 20 subjects with Crohn's disease (CD), 22 with ulcerative colitis (UC) and 15 controls. In each subject, biopsies were taken from various left-colonic locations. Gene and protein expression of GPR30 was quantified using real time RT-PCR or Western blot.

Results: GPR30 mRNA and protein expression were detected in all tested colonic tissues. No significant differences in GPR30 gene expression were observed. In non-inflamed areas, GPR30 protein was strongly increased in CD patients, but moderately in UC patients ( $\mathrm{p}=0.014$ and $\mathrm{p}=0.143$, respectively, vs. controls). In CD patients, a significantly lower GPR30 protein content in inflamed than in non-inflamed tissue was observed ( $\mathrm{p}=0.039)$. The change was independent of patient gender.

Conclusion: Our observations indicate that GPR30 may play a role in the development and progression of inflammatory lesions in IBD, thus affecting disease severity, and consequently IBD treatment. Therefore, GPR30 may become an attractive target for novel anti-IBD drugs, particularly in CD.
\end{abstract}

Key words: GPR30 - inflammatory bowel diseases - Crohn's disease - ulcerative colitis - biological therapy.

Abbreviations: CRP: C-reactive protein; C-IBS: constipation-predominant IBS; CD: Crohn's disease; D-IBS: diarrhea-predominant IBS; ER: Estrogen; GPER: G protein - coupled estrogen receptor 1; GPR30: G protein-coupled receptor 30; GI: gastrointestinal; GAPDH: glyceraldehyde 3-phosphate dehydrogenase; IBD: inflammatory bowel diseases; IL: Interleukin; ICAM-1: intracellular cell adhesion molecule-1; IBS: irritable bowel syndrome; PDL: periodontal ligament; Th: T helper; TNF- $\alpha$ : tumor necrosis factor- $\alpha$; UC: ulcerative colitis; VCAM-1: vascular cell adhesion molecule-1; WBC: white blood cells.

\section{INTRODUCTION}

Inflammatory bowel diseases (IBD) constitute a large group of chronic disorders of the gastrointestinal (GI) tract, which are characterized by chronic granulomatous inflammation with periods of exacerbations and remissions. The most common representatives within this group are Crohn's disease (CD) and ulcerative colitis (UC) [1]. The pathophysiology of the intestinal lesions in IBD is not entirely understood and many factors, including genetic, microbial, and environmental are believed to trigger the disease [2]. Recent studies suggest a strong impact of the immune system hyperactivation and elevated pro-inflammatory cytokine levels on the development of IBD [3]. Crohn's disease is associated with an exaggerated Th1 mediated response, characterized by enhanced production of interleukin (IL)-1, IL-2, IL-6, IL-12, IL-18, TNF- $\alpha$ and IFN- $\gamma$. On the other hand, in UC there is an enhanced production of Th2 cytokines, IL-4, IL-5, and IL10. However, this classic view of Th1/Th2 mutually exclusive has recently been challenged, as an increased number of IL-17 producing cells (Th17) has been found in samples from patients with both CD and UC [4].

The major IBD symptoms include abdominal pain, diarrhea, blood in the feces, weight loss and fatigue. The idiopathic 
inflammatory intestinal process related to IBD is strongly associated with a decreased patient's quality of life and requires advanced clinical intervention. However, a significant rate of loss of response or even the lack of any therapeutic effect is often observed with currently available anti-IBD treatments. Therefore, novel potential drug targets are now being investigated [1-3].

The design of novel therapeutics is impaired by our incomplete understanding of the pathophysiology of IBD and consequently poor insight into the changes in the immune system during IBD development. Several newly described receptors and pathways that may be involved in pathological immunological response in IBD are currently regarded as being the potential target for future anti-IBD drugs. These include recently de-orphanized receptors, i.e. proteins that have a structure similar to that of other identified receptors, but for which the first endogenous ligand has been recently identified [5]. Of all new de-orphanized receptors, the G protein - coupled receptor 30 (GPR30), also known as the G protein - coupled estrogen receptor 1 (GPER) is of particular interest [6].

Female sex hormones, estrogens, are known to exert antiatherogenic and anti-inflammatory effects [7]. Estrogen (ER) effects are mediated by activation of three different receptors: classical estrogen receptors ER $\alpha$ and ER $\beta$, and GPR30 [8-11]. It has been shown that the activation of GPR30 blocks the immunological pathways dependent on pro-inflammatory proteins, such as tumor necrosis factor- $\alpha$ (TNF- $\alpha$ ), intracellular cell adhesion molecule-1 (ICAM-1) and vascular cell adhesion molecule-1 (VCAM-1) [7]. However, very little is known about the GPR30 protein expression in the GI tract and its role in the development of IBD.

The aim of this pilot study was to determine whether GPR30 is expressed in the colonic tissue of IBD patients and if so, whether the GPR30 expression differs between non-IBD and IBD patients.

\section{METHODS}

\section{Study group}

Fifty-seven patients divided into three groups were enrolled in the study: controls $(n=15), C D(n=20)$ and UC $(n=22)$ patients. The patients were matched by age; additionally, the IBD patients were matched by sex. The control group included healthy subjects that were diagnosed as IBD-free by colonoscopy and the results confirmed by histopathological examination. None of the female subjects enrolled in the study were in the menopausal phase. In each participating subject two endoscopic biopsies during colonoscopy examination were taken from different colonic locations. The inclusion criteria for the study groups were based on the diagnosis according to clinical, radiological, endoscopic, and histological criteria recommended by the European Crohn's and Colitis Organization. The exclusion criteria were colorectal cancer, a history of cardiovascular disease, chronic pulmonary and kidney disease, allergy, diabetes, lichen planus, psoriasis, atopic dermatitis and other autoimmune skin lesions.

\section{Sample collection}

Endoscopic specimens obtained with pinch biopsy forceps contained mucosa (epithelium and the lamina propria) down to the muscularis mucosae. In each subject undergoing colonoscopy after signing an informed consent, two endoscopic biopsy specimens were prelevated from different colonic inflamed and non-inflamed areas (IBD patients: CD and UC), and in controls from different non-inflamed colonic areas. In all IBD patients the endoscopic biopsies from macroscopic inflamed and non-inflamed areas were drawn. The colonic samples were stored at $-80^{\circ} \mathrm{C}$ for further biochemical analysis. Based on additional biopsy specimens stored in $10 \%$ formalin the inflammatory involvement of the tissue was confirmed in histopathological routine H\&E staining. Tissue was considered non-inflamed if there was an absence of macroscopic or histological evidence of inflammation.

\section{RNA isolation}

Total RNA extraction was performed using Tri Reagent (Sigma Aldrich, Germany) and PureLink RNA Mini Kit (Life Technologies, USA). Briefly, the tissue was minced and homogenized in Tri Reagent, after centrifugation and separation of the phases, the upper, aqueous phase was mixed 1:1 (v/v) with the lysis buffer and loaded onto the column, subsequent steps were conducted according to manufacturer's protocol.

The quality and quantity of total RNA was estimated spectrophotometrically with BioPhotometer plus (Eppendorf, Germany). The sample was characterized with A260 nm/A280 $\mathrm{nm}$ ratio, which was in the range of 1.79-2.01.

\section{Reverse transcription}

cDNA synthesis was performed with the RevertAid First Strand cDNA Synthesis Kit (Fermentas, Canada) in accordance with the manufacturer's protocol. Total RNA $(1 \mu \mathrm{g})$ was used in reverse transcription reaction in a total volume of $20 \mu \mathrm{l}$ with the following three step incubation: $25^{\circ} \mathrm{C}$ for $5 \mathrm{~min}, 42^{\circ} \mathrm{C}$ for $60 \mathrm{~min}$ and $70^{\circ} \mathrm{C}$ for $5 \mathrm{~min}$.

\section{Quantitative real-time RT-PCR}

For the quantification of mRNA expression, we applied the real-time fluorescence detection PCR method with FAM dyelabeled TaqMan probes (Applied Biosystems, USA). Values obtained for studied genes were normalized to the expression of GAPDH (glyceraldehyde 3-phosphate dehydrogenase) gene as an endogenous control. The catalog numbers for the probes used are as follows: GPR30 - Hs01922715_s1, GAPDH - Hs99999905_m1. The real-time reaction mixture was prepared in a total volume of $10 \mu \mathrm{l}$ and consisted of 0.5 $\mu \mathrm{l}$ cDNA, $5 \mu \mathrm{l}$ TaqMan Gene Expression Master Mix, $0.5 \mu \mathrm{l}$ TaqMan Gene Expression Assays and $4 \mu \mathrm{l}$ RNA-free water and was performed as triplicate. The cDNA was amplified in Mastercycler Realplex (Eppendorf, Germany). Cycle parameters were as follows: initial denaturation at $95^{\circ} \mathrm{C}$ for $10 \mathrm{~min}$, followed by 40 cycles of sequential incubations at $95^{\circ} \mathrm{C}$ for $15 \mathrm{~s}$ and at $60^{\circ} \mathrm{C}$ for $1 \mathrm{~min}$.

The fluorescent dye emission was a function of the cycle number. The initial amount of the template was evaluated as a $\mathrm{Ct}$ parameter. $\mathrm{Ct}$ value was the threshold cycle number at which PCR amplification reached a significant threshold. The number of the cycle was linearly correlated with logarithmic value of RNA quantity. The relative expression level normalized to GAPDH was calculated as $2 \wedge\left[-\left(\mathrm{Ct}_{\mathrm{GPR} 30}-\mathrm{Ct}_{\mathrm{GAPDH}}\right)\right] \times 1000$. 


\section{Protein extraction and quantification}

Tissue scraps were homogenized following a protocol provided with tissue lysis buffer for the whole cell lysate (SigmaAldrich). Briefly, around $10 \mathrm{mg}$ of tissue was added to $1 \mathrm{ml}$ of tissue lysis buffer (Sigma-Aldrich) and homogenized on ice for 30 seconds with tissue raptor (IKE, Germany). Next, the samples were centrifuged $10,000 \mathrm{xg}, 10 \mathrm{~min}, 4^{\circ} \mathrm{C}$ and protein level was assayed using modified Lowry's method.

\section{GPR30 detection by Western blot}

The GPR30 and GAPDH proteins content in biopsy specimens were detected using the immunoenzymatic (Western blot) method with specific primary antibodies against GPR30 and GAPDH proteins. Equal protein amounts of tissue extracts were separated by SDS-PAGE. After electrophoresis, proteins were transferred on nitrocellulose and incubated overnight at $4^{\circ} \mathrm{C}$ with consecutive primary rabbit anti-human monoclonal antibodies at concentrations 1:1,000 in PBS for GPR30, and 1:3,000 in PBS for GAPDH (Santa Cruz, Cell Signaling, UK and USA, respectively). Next, the secondary HRP-conjugated donkey antibodies were used at concentrations 1:5,000 in PBS+Tween $20(0.05 \%)$ for GPR30 and 1:1,000 in PBS for GAPDH (Santa-Cruz). The pico- or femtoluminol reagents (Thermo Scientific) and X-ray films (Thermo-Scientific) were used to visualize the reaction. Finally, signal intensity was quantified using ImageJ software (Canada) and normalized to GAPDH.

Each assay was performed in triplicates with tissue samples from different donors.

\section{Statistical analysis}

Continuous demographic and biochemical data are presented as means \pm SEM, while demographic categorical data were described with absolute frequencies and percentages.
Statistical analysis was performed using Prism 5.0 (GraphPad Software Inc., La Jolla, CA, USA). An analysis of variance (oneway ANOVA) followed by Newman-Keuls post hoc testing and Bonferroni correction post-test were used to calculate differences. $\mathrm{P}$ values $<0.05$ were considered statistically significant. Ct values obtained for reference gene were tested using Grubbs test for possible outliers.

\section{Ethics statement}

The study was conducted in accordance with the ethical principles of the 1975 Declaration of Helsinki and the Committee of Bioethics of Medical University of Lodz approved the study protocol (RNN/515/13/KB). All participating subjects gave written, informed consent prior to enrollment.

\section{RESULTS}

\section{Patients' characteristics}

Fifty-seven patients who were hospitalized at the Department of Gastroenterology at the Medical University of Lodz, Poland were enrolled in our study: 28 women and 29 men. Detailed demographic characteristics, laboratory findings and treatment history are presented in Table I. The analyzed groups (Control, CD, and UC) were homogeneous in terms of age and gender of the patients. The percentage of smokers in the CD and UC groups was similar (20\% and $27 \%$, respectively; $\mathrm{p}=0.581$ ).

The white blood cell (WBC) levels in all analyzed groups were comparable $(\mathrm{p}=0.891)$ and no gender-related significant difference in WBC concentration was observed $(\mathrm{p}=0.795)$. The $\mathrm{CD}$ and UC patients had a weak tendency to elevated blood C-reactive protein (CRP) levels compared to the control group $(\mathrm{p}=0.061$ and $\mathrm{p}=0.172$, respectively).

Table I. Detailed demographic characteristics and laboratory findings in the patients with inflammatory bowel diseases and controls enrolled into the study.

\begin{tabular}{|c|c|c|c|c|c|}
\hline & & Crohn's disease & Ulcerative colitis & Control group & $\mathrm{p}$-value \\
\hline Subjects, n (\%) & & 20 & 22 & 15 & NA \\
\hline \multirow[t]{2}{*}{ Gender, n (\%) } & women & $10(50 \%)$ & $11(50 \%)$ & $7(46 \%)$ & 0.976 \\
\hline & men & $10(50 \%)$ & $11(50 \%)$ & $8(53 \%)$ & \\
\hline Age, years & $24.3 \pm 3.6$ & $26.7 \pm 4.4$ & $25.7 \pm 4.4$ & 0.562 & \\
\hline BMI, kg/m² & $21.1 \pm 2.4$ & $21.0 \pm 1.7$ & $21.6 \pm 1.3$ & 0.653 & \\
\hline 5-ASA/SASP & $11(55 \%)$ & $15(68 \%)$ & NA & 0.379 & \\
\hline \multirow[t]{4}{*}{ Corticosteroid history, n (\%) } & Never used & $2(10 \%)$ & $3(14 \%)$ & $13(87 \%)$ & NA \\
\hline & $\leq 1$ year & $4(20 \%)$ & $3(14 \%)$ & $2(13 \%)$ & \\
\hline & $>1$ year to $\leq 2$ years & $4(20 \%)$ & $10(46 \%)$ & $0(0 \%)$ & \\
\hline & $>2$ years & $10(50 \%)$ & $6(26 \%)$ & $0(0 \%)$ & \\
\hline Hematocrit, \% & & $39.4 \pm 9.4$ & $38.4 \pm 9.9$ & $43.6 \pm 11.4$ & 0.325 \\
\hline White blood cell count, $\mathrm{x} 10^{3} / \mu \mathrm{l}$ & & $7.37 \pm 2.70$ & $6.97 \pm 2.61$ & $7.11 \pm 2.59$ & 0.891 \\
\hline Platelet count, $\mathrm{x} 10^{3} / \mu \mathrm{l}$ & & $329 \pm 149$ & $289 \pm 89$ & $246 \pm 47$ & 0.245 \\
\hline Mean platelet volume, fL & & $11.25 \pm 0.99$ & $10.89 \pm 0.91$ & $11.29 \pm 1.08$ & 0.783 \\
\hline CRP, mg/l & & $4.6 \pm 5.9$ & $3.8 \pm 5.1$ & $0.7 \pm 0.8$ & 0.054 \\
\hline
\end{tabular}

Data are presented as mean \pm standard deviation or number (percentage).

BMI: body mass index; 5-ASA: 5-aminosalicylate; SASP: sulfasalazine; CRP: C-reactive protein; NA: not applicable 


\section{GPR30 mRNA expression in the colonic tissue}

GPR30 mRNA was detected in all samples tested. The level of expression of GPR30 mRNA was comparable in noninflamed colonic tissues in all analyzed groups $(\mathrm{p}=0.572)$. Moreover, there were no differences in GPR30 mRNA expression in inflamed colonic tissues in the CD vs. UC patients $(\mathrm{p}=0.244)$. In addition, similar GPR30 mRNA expression levels in inflamed compared with non-inflamed colonic tissue were observed in the CD group $(\mathrm{p}=0.319)$ and in the UC group $(\mathrm{p}=0.244)$ (Fig. 1). Finally, no significant differences of GPR30 mRNA expression in CD and UC patients were observed when patients were divided by sex (CD: $p=0.854$; UC: $p=0.675)$.

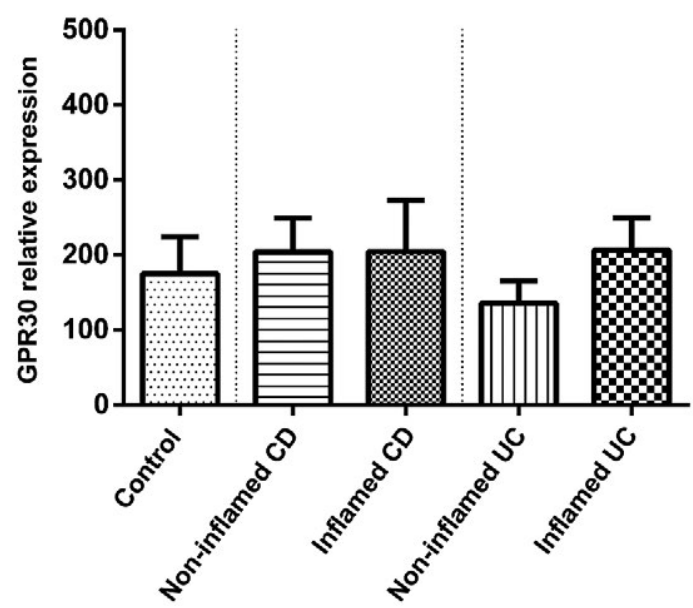

Fig. 1. GPR30 mRNA expression in all analyzed colonic tissues.

\section{GPR30 protein expression in the colonic tissue}

The GPR30 protein expression was detected in all tested colonic tissues. In non-inflamed colonic tissues, there was a significant difference in GPR30 protein expression among all analyzed groups ( $p=0.0496)$ (Fig. 2). Namely, the level of GPR30 protein was significantly increased in CD patients $(1.501 \pm 0.270$ vs. $0.273 \pm 0.070, p=0.014)$, but only moderately and not significantly in UC patients $(1.152 \pm 0.335$ vs. $0.273 \pm 0.070 ; \mathrm{p}=0.143)$, as compared with controls.

We further analyzed the GPR30 protein levels in the inflamed vs. non-inflamed colonic tissues. There were no significant differences in GPR30 protein expression between CD and UC either in non-inflamed $(1.501 \pm 0.270$ vs. $1.152 \pm 0.335$; $\mathrm{p}=0.432)$ (Fig. 2) or inflamed colonic tissues $(0.845 \pm 0.231$ vs. $1.134 \pm 0.337 ; \mathrm{p}=0.491$ ) (Fig. 3). In the CD patients, a significantly lower GPR30 protein content in the inflamed than in noninflamed tissue was observed $(0.690 \pm 0.186$ vs. $1.437 \pm 0.285$; $\mathrm{p}=0.039$ ) (Fig. 4). In the UC patients, no difference in colonic GPR30 protein level in the inflamed and non-inflamed tissues was observed ( $1.134 \pm 0.337$ vs. $1.071 \pm 0.411 ; p=0.909)$ (Fig. 5). When patients were divided by sex, there were no differences in the colonic GPR30 protein expression between female and male inflamed, as well as between female and male non-inflamed tissues (Fig. 6). However, a significantly lower level of GPR30 in inflamed compared to non-inflamed tissues in female CD patients was observed; a similar trend was observed for male CD patients (men: $0.854 \pm 0.381$ vs. $1.766 \pm 0.463 ; \mathrm{p}=0.032$; women: $0.834 \pm 0.272$ vs. $1.192 \pm 0.210 ; \mathrm{p}=0.041)$.

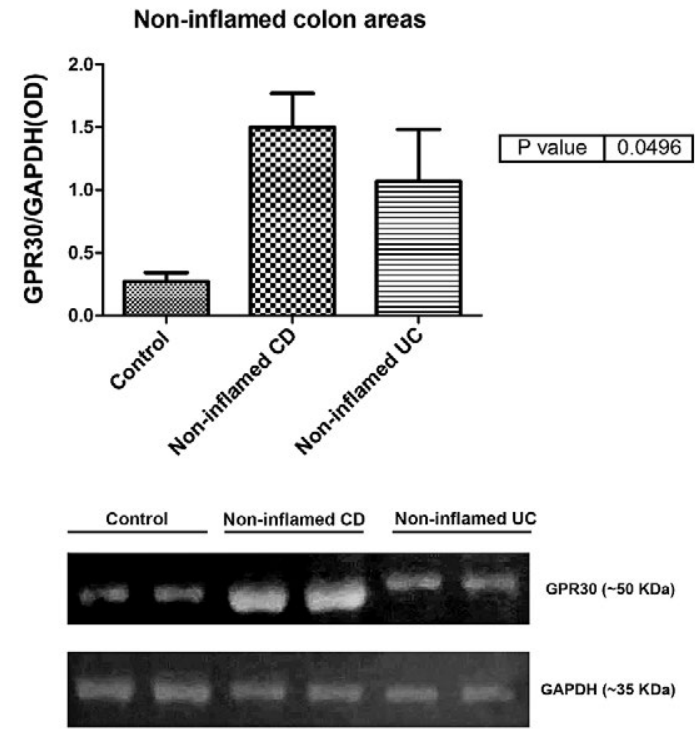

Fig. 2. Significant difference in GPR30 protein expression between all analyzed groups in non-inflamed colonic tissues. Data presented as means \pm SEM (top panel); representative blot (bottom panel).

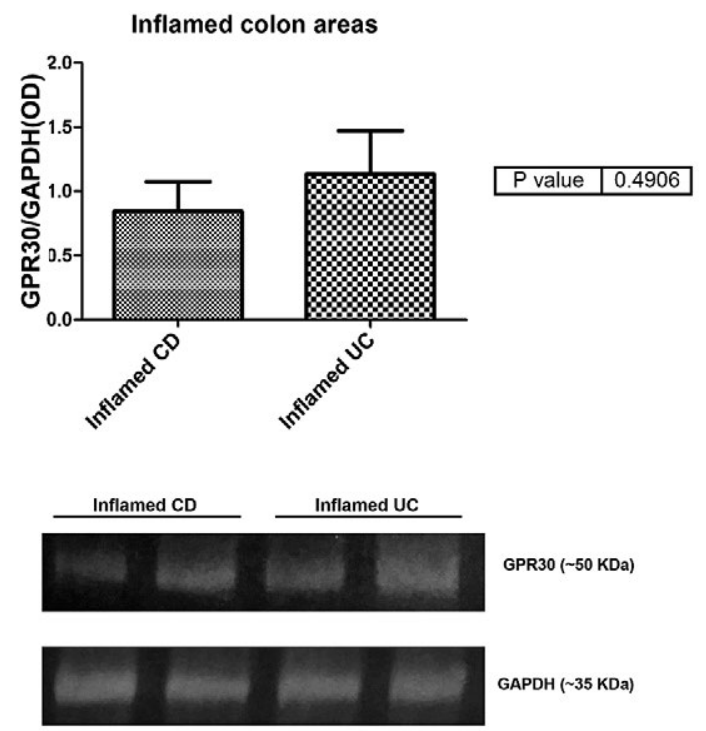

Fig. 3. No difference in GPR30 protein expression in inflamed colonic tissues. Data presented as means \pm SEM (top panel); representative blot (bottom panel).

\section{DISCUSSION}

In this study we provide evidence that GPR30 is expressed in colonic tissue specimens and may be involved in the intestinal inflammatory balance. Importantly, we observed higher GPR30 protein levels in IBD patients than in healthy controls, which may underline its role in the development of colonic inflammatory lesions. Of note, we also found differences in GPR30 protein expression between non-inflamed and inflamed areas of colonic tissue of CD, but not UC patients.

The G-protein coupled receptor GPR30 was identified in 1997, but its role was established only in 2005 [8, 12]. It was shown that GPR30 is involved, among others, in the 


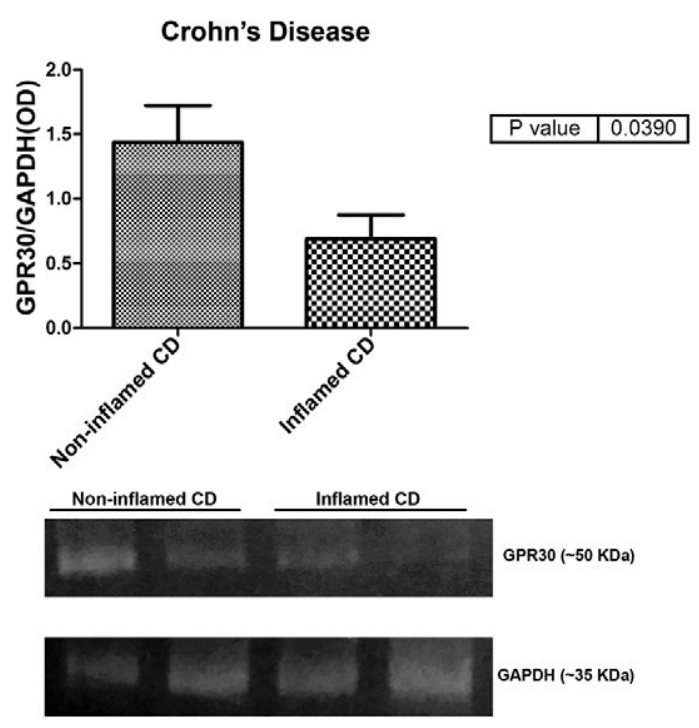

Fig. 4. Significant difference in GPR30 protein expression in $\mathrm{CD}$ patients in non-inflamed vs. inflamed colonic tissues. Data presented as means \pm SEM (top panel); representative blot (bottom panel).

activation of actin polymerization and the inhibition of cellular proliferation in human umbilical vein endothelial cells [13]; others found that the GPR30 agonist inhibits cardiac cell growth [14]. Recent studies implicate the role of GPR30 in aggressive forms of breast, ovarian and endometrial cancers [15]. GPR30 has also become an interesting target for studies on the GI tract. Qin et al. showed differential distribution of GPR30, ER $\alpha$ and ER $\beta$ in human colonic mucosa [16]. It was also observed that the expression of GPR30 in the cytoplasm of mast cells and GPR30-positive cells was significantly higher in diarrhea-predominant IBS (D-IBS) patients than in constipation-predominant IBS (C-IBS) patients and healthy subjects [16]. Noteworthy, ER $\alpha$ and $\operatorname{ER} \beta$ were largely absent in mast cells in colonic mucosa and no difference in immunostaining for ER $\alpha$ and ER $\beta$ was found among these three groups.

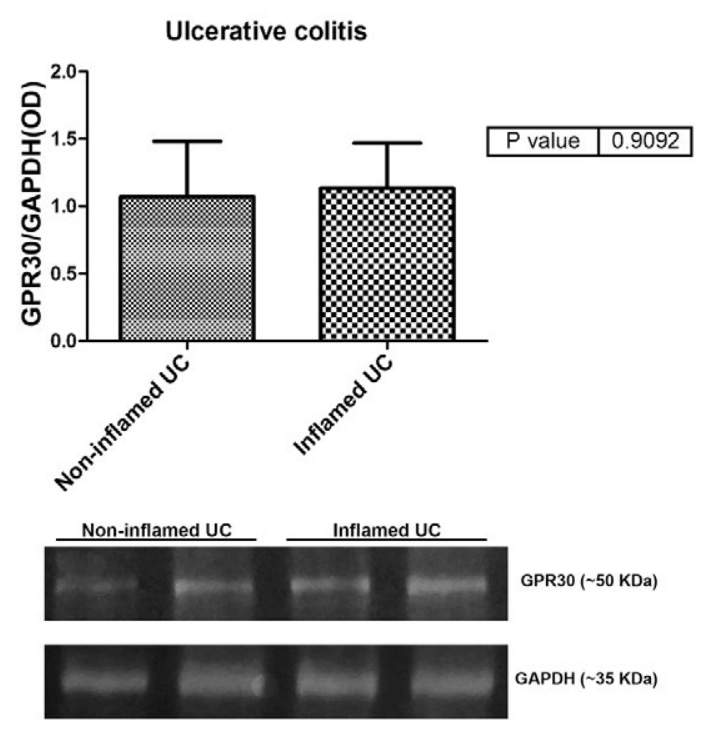

Fig. 5. No difference in GPR30 protein expression in UC patients in non-inflamed and inflamed colonic tissues. Data presented as means \pm SEM (top panel); representative blot (bottom panel).

Our study suggests that GPR30 may play a crucial role in intestinal inflammation and could be considered as a potential target for anti-inflammatory treatment. This is in line with other recent studies, in which the activation of GPR30 produced anti-inflammatory effects. For example, Blasko et al. and Weil et al. demonstrated the anti-inflammatory effect on GPR30 activation in rodent models of multiple sclerosis and ischemia-reperfusion injury [17-18]. Similarly, Chakrabarti et al. detected GPR30 protein expression in cultured human endothelial cells, interestingly with a predominant localization in the cell nuclei, and observed that the activation of the endothelial GPR30 attenuated the TNFa-induced upregulation of proinflammatory leukocyte adhesion molecules [7]. Of note, previously published data also indicated a possible implication of GPR30 in the inflammatory processes in the GI tract. Luo et al. found that the GPR30 expression in human
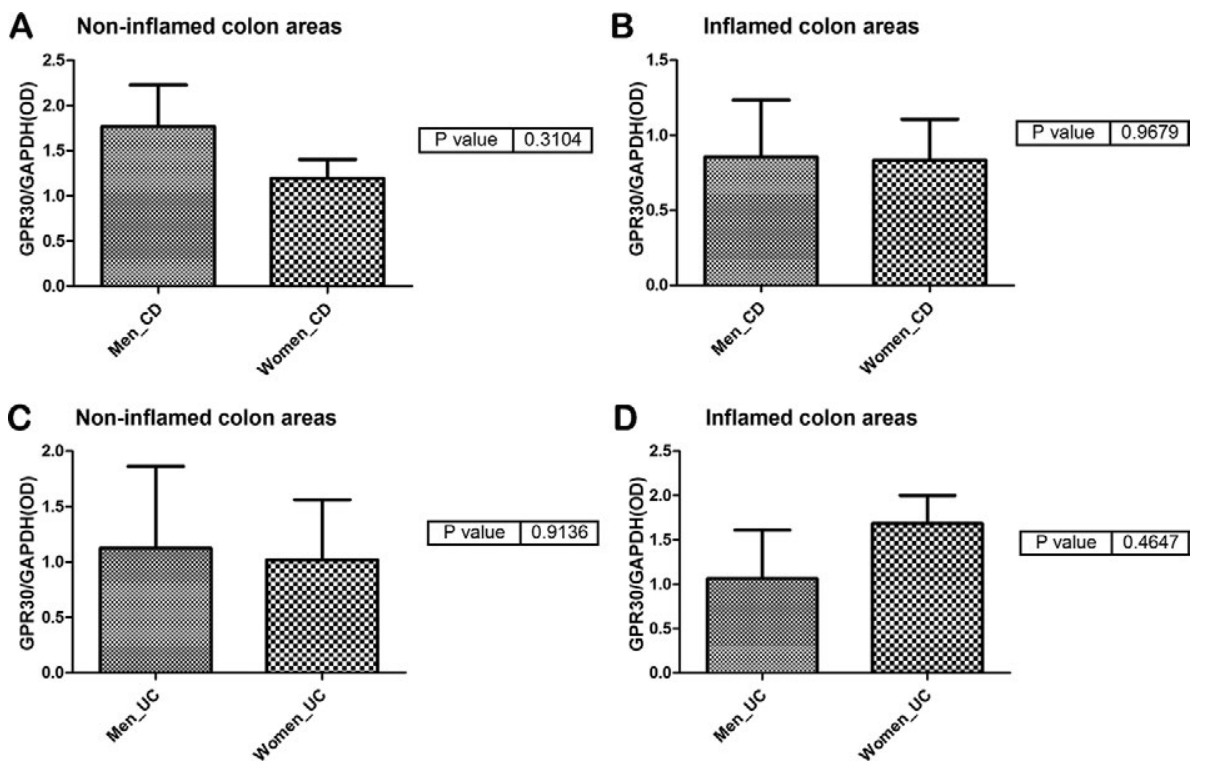

Fig. 6. GPR30 protein expression sex related differences in the non-inflamed and inflamed colonic in $\mathrm{CD}(\mathrm{A}, \mathrm{B})$ and $\mathrm{UC}(\mathrm{C}, \mathrm{D})$ patients. 
periodontal ligament (PDL) cells is regulated by IL-1 $\beta$ [19]. They also demonstrated that an increase in GPR30 level in human PDL cells leads to the activation of multiple signaling pathways, including MAPK, NF- $\mathrm{kB}$ and PI3K dependent. Therefore, it has been suggested that GPR30 represents a novel target regulated by steroid hormones in PDL cells.

The role of estrogens in the inflammatory process is controversial [20] and their complex effects mediated through ERs and GPR30 remain largely unknown. For example, estradiol supplementation of ovariectomized mice ameliorated the severity of colitis [21]. Villa et al. [22] showed that the activation of the intracellular estrogen receptor by estradiol shortened the LPS-induced pro-inflammatory phase and, by influencing the intrinsic and extrinsic programs, triggered the resolution of inflammation in RAW 264.7 cells through the regulation of the SOCS3 and STAT3 signaling pathways. Moreover, estradiol levels increased during anti-TNFa therapy in adolescents with $\mathrm{CD}$ [23]. On the other hand, it was demonstrated that the concomitant activation of GPR30 and either ERa or ER $\beta$ prevented the attenuation of endothelial inflammation, which may suggest a direct inhibitory effect of classical ERs on GPR30-mediated activity. Ding et al. observed opposing actions of ER $\alpha$ and GPR30 agonists on ERK phosphorylation in cultured vascular smooth muscle cells [24]. Furthermore, a study conducted by Gao et al. showed opposing effects of GPR30 and classical estradiol signaling on cell proliferation in the mouse uterine tissue involving modulation of ERK phosphorylation [25]. Finally, Lu et al. observed that estrogen-mediated visceral hypersensitivity is GPR30-dependent in models without colonic inflammation [26]. To sum up, the complex relationship between ERs and GPR30 and its role in the inflammatory process in the gut, along with quantification of estradiol levels in IBD patients requires further investigation. In our study, there were no gender-related differences in the colonic expression of GPR30, which may suggest that estrogen levels do not play any role in GPR30 signaling related to intestinal inflammation. This finding is in opposition to the study conducted by Rowlands et al., who suggested that the higher level of estrogen may be associated with anti-inflammatory and anti-atherogenic effects on the female vasculature [13]. The anti-inflammatory effect of estrogen was confirmed by the observation that premenopausal women are relatively protected against myocardial infarction and stroke compared to age-matched men [27]. However, in our opinion, further studies should be performed to investigate a possible association between estrogen levels and intestinal inflammatory process.

Noteworthy, in CD, but not UC patients we observed a significantly lower GPR30 protein content in inflamed than in non-inflamed tissue. We hypothesize that the differences found between $\mathrm{CD}$ and UC patients could be due to the association of CD and UC with Th1 and Th2-dependent pathways and its consequences during the resolution of inflammation in the colonic tissue. However, a more detailed picture of GPR30 expression in intestinal epithelial cells vs. recruited immune cells is also needed. There are already several lines of evidence showing that GPR30 is expressed in macrophages, neutrophils and lymphocytes, e.g. Tregs [27-32].
Changes of GPR30 expression exclusively on protein but not at mRNA level may suggest that reduced protein turnover and increased protein stability in CD patients take place. The lack of compatibility between alternation of protein and mRNA expression confirms that there is no simple and direct relation between transcriptome and proteome, and GPR30-mediated regulation in inflammatory bowel diseases involves various mechanisms.

\section{CONCLUSION}

GPR30 is detectable in the colonic tissue of IBD patients. Importantly, higher protein levels of GPR30 characterize the non-inflamed areas of colonic tissue in $\mathrm{CD}$, but not in UC patients. Furthermore, the up-regulation of GPR30 in noninflamed areas of $\mathrm{CD}$ patients seems to be gender-independent. Our observations indicate that GPR30 may play a role in the inflammatory process in IBD patients, thus affecting disease severity, as well as the response to treatment. Depending on the outcomes of further investigation, GPR30 receptors may become an attractive target for novel drugs in the treatment of IBD, particularly in CD patients.

Conflicts of interest: Nothing to disclose.

Authors' contributions: M.W. and A.S.-W.: literature search, analysis and interpretation, writing of the manuscript. M.W., A.S.-W. and J.F.: manuscript development. M.W., A.S.-W., M.W.-J. and K. S.-M.: patient enrollment and clinical evaluation; M.W., A.S.-W., A. P.-P., A. C. and D. J.: laboratory experiments and data analysis. W.M.K., J.F., K. S.-M. and M.W.-J.: manuscript revision.

Acknowledgement: This research was supported by the grants from the Medical University of Lodz (\#503/1-156-04/503-01 to JF) and the National Science Center (2015/17/N/NZ5/00336 to DJ).

\section{REFERENCES}

1. Xavier RJ, Podolsky DK. Unravelling the pathogenesis of inflammatory bowel disease. Nature 2007;448:427-434. doi:10.1038/nature06005

2. Frolkis A, Dieleman LA, Bakema $\mathrm{H}$, et al. Environment and the inflammatory bowel diseases. Can J Gastroenterol 2013;27:e18-e24.

3. Shanahan F, Bernstein CN. The evolving epidemiology of inflammatory bowel disease. Curr Opin Gastroenterol 2009;25:301-305. doi:10.1097/ MOG.0b013e32832b12ef

4. Geng X, Xue J. Expression of Treg/Th17 cells as well as related cytokines in patients with inflammatory bowel disease. Pak J Med Sci 2016;32:1164-1168. doi: 10.12669/pjms.325.10902

5. Levoye A, Dam J, Ayoub MA, Guillaume JL, Jockers R. Do orphan G-protein-coupled receptors have ligand-independent functions? New insights from receptor heterodimers. EMBO Rep 2006;7:1094-1098. doi:10.1038/sj.embor.7400838

6. Wasilewski A, Storr M, Zielińska M, Fichna J. Role of G proteincoupled orphan receptors in intestinal inflammation: novel targets in inflammatory bowel diseases. Inflamm Bowel Dis 2015;21:666-673. doi:10.1097/MIB.0000000000000258

7. Chakrabarti S, Davidge ST. G-protein coupled receptor 30 (GPR30): a novel regulator of endothelial inflammation. PLoS One 2012;7: e52357. doi:10.1371/journal.pone.0052357 
8. Revankar CM, Cimino DF, Sklar LA, Arterburn JB, Prossnitz ER. A transmembrane intracellular estrogen receptor mediates rapid cell signaling. Science 2005;307:1625-1630. doi:10.1126/ science.1106943

9. Filardo EJ, Thomas P. GPR30: a seven-transmembrane-spanning estrogen receptor that triggers EGF release. Trends Endocrinol Metab 2005;16:362-367. doi:10.1016/j.tem.2005.08.005

10. Ihionkhan CE, Chambliss KL, Gibson LL, Hahner LD, Mendelsohn ME, Shaul PW. Estrogen causes dynamic alterations in endothelial estrogen receptor expression. Circ Res 2002;91:814-820. doi:10.1161/01. RES.0000038304.62046.4C

11. Ba ZF, Chaudry IH. Role of estrogen receptor subtypes in estrogeninduced organ-specific vasorelaxation after trauma-hemorrhage. Am J Physiol Heart Circ Physiol 2008;295:H2061-H2067. doi:10.1152/ ajpheart.00707.2008

12. Carmeci C, Thompson DA, Ring HZ, Francke U, Weigel RJ. Identification of a gene (GPR30) with homology to the G-protein-coupled receptor superfamily associated with estrogen receptor expression in breast cancer. Genomics 1997;45:607-617. doi:10.1006/geno.1997.4972

13. Rowlands DJ, Chapple S, Siow RC, Mann GE. Equol-stimulated mitochondrial reactive oxygen species activate endothelial nitric oxide synthase and redox signaling in endothelial cells: roles for F-actin and GPR30. Hypertension 2011;57:833-840. doi:10.1161/ HYPERTENSIONAHA.110.162198

14. Resanovic I, Rizzo M, Zafirovic S, et al. Anti-atherogenic effects of 17 $\beta$-estradiol. Horm Metab Res 2013;45:701-708. doi:10.1055/s-0033-1343478

15. Nayak TK, Dennis MK, Ramesh C, et al. Influence of charge on cell permeability and tumor imaging of GPR30-targeted 111in-labeled nonsteroidal imaging agents. ACS Chem Biol 2010;5:681-690. doi: $10.1021 / \mathrm{cb} 1000636$

16. Qin B, Dong L, Guo X, et al. Expression of G protein-coupled estrogen receptor in irritable bowel syndrome and its clinical significance. Int J Clin Exp Pathol 2014;7:2238-2246.

17. Blasko E, Haskell CA, Leung S, et al. Beneficial role of the GPR30 agonist G-1 in an animal model of multiple sclerosis. J Neuroimmunol 2009;214:67-77. doi:10.1016/j.jneuroim.2009.06.023

18. Weil BR, Manukyan MC, Herrmann JL, et al. Signaling via GPR30 protects the myocardium from ischemia/reperfusion injury. Surgery 2010;148:436-443. doi:10.1016/j.surg.2010.03.011

19. Luo LJ, Liu F, Lin ZK, et al. Genistein regulates the IL-1 beta induced activation of MAPKs in human periodontal ligament cells through G protein-coupled receptor 30. Arch Biochem Biophys 2012;522:9-16. doi:10.1016/j.abb.2012.04.007
20. Straub RH. The complex role of estrogens in inflammation. Endocr Rev 2007;28:521-574. doi:10.1210/er.2007-0001\#sthash.7c4Qy79y.dpuf

21. Bábíčková J, Tóthová L', Lengyelová E, et al. Sex differences in experimentally induced colitis in mice: a role for estrogens. Inflammation 2015;38:1996-2006. doi:10.1007/s10753-015-0180-7

22. Villa A, Rizzi N, Vegeto E, Ciana P, Maggi A. Estrogen accelerates the resolution of inflammation in macrophagic cells. Sci Rep 2015;5:15224. doi:10.1038/srep 15224

23. DeBoer MD, Thayu M, Griffin LM, et al. Increases in Sex Hormones during Anti-Tumor Necrosis Factor a Therapy in Adolescents with Crohn's Disease. J Pediatr 2016;171:146-152.e1-2. doi:10.1016/j. jpeds.2016.01.003

24. Ding Q, Gros R, Limbird LE, Chorazyczewski J, Feldman RD. Estradiol-mediated ERK phosphorylation and apoptosis in vascular smooth muscle cells requires GPR 30. Am J Physiol Cell Physiol 2009;297:C1178-C1187. doi:10.1152/ajpcell.00185.2009

25. Gao F, Ma X, Ostmann AB, Das SK. GPR30 activation opposes estrogen-dependent uterine growth via inhibition of stromal ERK1/2 and estrogen receptor alpha (ERalpha) phosphorylation signals. Endocrinology 2011;152:1434-1447. doi:10.1210/en.2010-1368

26. Lu CL, Hsieh JC, Dun NJ, et al. Estrogen rapidly modulates 5-hydroxytrytophan-induced visceral hypersensitivity via GPR30 in rats. Gastroenterology 2009;137:1040-1050. doi:10.1053/j. gastro.2009.03.047

27. Regitz-Zagrosek V. Therapeutic implications of the gender-specific aspects of cardiovascular disease. Nat Rev Drug Discov 2006;5:425-438. doi: $10.1038 /$ nrd2032

28. Schneider AE, Kárpáti E, Schuszter K, et al. A dynamic network of estrogen receptors in murine lymphocytes: fine-tuning the immune response. J Leukoc Biol 2014;96:857-872. doi:10.1189/jlb.2A0214-080RR

29. Szwejser E, Maciuszek M, Casanova-Nakayama, A et al. A role for multiple estrogen receptors in immune regulation of common carp. Dev Comp Immunol 2017;66:61-72. doi:10.1016/j.dci.2016.04.003

30. Pelekanou V, Kampa M, Kiagiadaki F, et al. Estrogen anti-inflammatory activity on human monocytes is mediated through cross-talk between estrogen receptor ERa36 and GPR30/GPER1. J Leukoc Biol 2016;99:333-347. doi:10.1189/jlb.3A0914-430RR

31. Pierdominici M, Maselli A, Varano B, et al. Linking estrogen receptor $\beta$ expression with inflammatory bowel disease activity. Oncotarget 2015;6:40443-40451. doi:10.18632/oncotarget.6217

32. Brunsing RL, Owens KS, Prossnitz ER. The G protein-coupled estrogen receptor (GPER) agonist G-1 expands the regulatory T-cell population under TH17-polarizing conditions. J Immunother 2013;36:190-196. doi:10.1097/CJI.0b013e31828d8e3b 